\title{
One-step, low-temperature fabrication of CdS quantum dots by watermelon rind: a green approach
}

Rajasekhar Lakshmipathy'

Nallani Chakravarthula

Sarada ${ }^{2}$

K Chidambaram ${ }^{3}$

Sk Khadeer Pasha ${ }^{3}$

'Centre for Material Science, KCG College of Technology, Chennai, Tamil Nadu, India; ${ }^{2}$ Environmental and Analytical Chemistry Division, ${ }^{3}$ Material Physics Division, School of Advanced Sciences, VIT University, Vellore, Tamil Nadu, India
Correspondence: Shaik Khadeer Pasha Material Physics Division, School of Advanced Sciences, VIT University, Vellore, Tamil Nadu, India 632014

Tel +9| 9894665388

$\mathrm{Fax}+914162243092$

Email khadheerbasha@gmail.com
This article was published in the following Dove Press journal:

International Journal of Nanomedicine

I October 2015

Number of times this article has been viewed

\begin{abstract}
We investigated the one-step synthesis of CdS nanoparticles via green synthesis that used aqueous extract of watermelon rind as a capping and stabilizing agent. Preliminary phytochemical analysis depicted the presence of carbohydrates which can act as capping and stabilizing agents. Synthesized CdS nanoparticles were characterized using UV-visible, Fourier transform infrared spectroscopy, X-ray diffraction, EDX, dynamic light scattering, transmission electron microscopy, and atomic force microscopy techniques. The CdS nanoparticles were found to be size- and shape-controlled and were stable even after 3 months of synthesis. The results suggest that watermelon rind, an agro-waste, can be used for synthesis of CdS nanoparticles without any addition of stabilizing and capping agents.
\end{abstract}

Keywords: green synthesis, nanoparticles, biomimetic, atomic force microscopy

\section{Introduction}

Cadmium sulfide (CdS) nanoparticles (NPs) are typical II-VI semiconductors with unique optical properties and tunable photoluminescence compared to their bulk counterparts on account of the size quantization effects. The preparation of CdS NPs has been carried out using various methods such as microwave heating, ${ }^{1}$ microemulsion synthesis, ${ }^{2}$ chemical synthesis, ${ }^{3}$ and ultrasonic irradiation. ${ }^{4}$ To fulfill the growing need for environmentally friendly NPs, researchers are using microorganisms for synthesis of various metal NPs. ${ }^{5}$ Nowadays, plant and agriculture waste extracts are used as reducing and capping agents for the synthesis of NPs. An extensive literature survey revealed that there are no reports on the synthesis of CdS NPs using agricultural wastes. Agricultural wastes are known to be rich in organic molecules and biopolymers which can play versatile roles in various areas. Agro-wastes and industrial byproducts are explored for a variety of applications, such as adsorption ${ }^{6}$ and corrosion and as precursors for activated carbon. Recently, the ability or potential of agro-wastes toward synthesis of noble NPs is being explored. Interestingly, fruit residues and wastes have proved to be good stabilizers for fabrication of NPs. However, the ability of fruit residues and wastes for the fabrication of metal sulfides and oxides are yet to be explored systematically. In view of this, the present study reports the feasibility of fabrication of CdS NPs by watermelon rind (WR), an agro-waste produced at high rates during summer.

WR consists of pectin, citrulline, cellulose, proteins, and carotenoids. ${ }^{7}$ These polymers are rich in functional groups such as hydroxyl (cellulose), amine (proteins), and carboxylic (pectin) that can easily bind inorganic materials. Recently, WR was reported to bind $\mathrm{Ni}^{2+}$ and $\mathrm{Co}^{2+}$ ions from aqueous solution. ${ }^{8}$ submit your manuscript | www.dovepress.com

Dovepress

http://dx.doi.org// 0.2147/1JN.S79988
International Journal of Nanomedicine 2015:10 (Suppl I:Challenges in biomaterials research) I83-I88 I 83

(c) (i) (5) 2015 Lakshmipathy et al. This work is published by Dove Medical Press Limited, and licensed under Creative Commons Attribution - Non Commercial (unported, v3.0) License. The full terms of the License are available at http:///creativecommons.org/licenses/by-nc/3.0/. Non-commercial uses of the work are permitted without any further permission how to request permission may be found at: http://www.dovepress.com/permissions.php 
This innovative research reports a one-step, simple approach for the "green" synthesis of CdS NPs using WR, an agro-waste. The phase, morphological, and elemental analysis of the as-synthesized CdS NPs are investigated.

\section{Materials and methods Preparation of extract}

WRs were obtained from a local fruit market, washed with tap water, and dried under sunlight for 7 days. The dried WR pieces were washed repeatedly with hot water $\left(70^{\circ} \mathrm{C}\right)$ to remove any soluble matter present and then dried in an oven at $85^{\circ} \mathrm{C}$ for 48 hours. To $50 \mathrm{~mL}$ of distilled water, $1 \mathrm{~g}$ of sieved WR was added, and the mixture was boiled in a water bath for 30 minutes to prepare an aqueous extract. The extract was then cooled to room temperature and filtered through $0.45 \mu \mathrm{m}$ filters, and this freshly prepared extract was used for synthesis. This aqueous extract was termed as WR aqueous extract (WRAE).

\section{Synthesis of CdS NPs}

To $20 \mathrm{~mL}$ of $0.25 \mathrm{M}$ cadmium chloride $\left(\mathrm{CdCl}_{2}\right)$ solution, $5 \mathrm{~mL}$ of sodium sulfide $\left(\mathrm{Na}_{2} \mathrm{~S}\right)$ was added until it attained an orange-yellow color indicating the formation of Cds; $10 \mathrm{~mL}$ of freshly prepared WRAE were added to the colored solution and stirred for 12 hours at $70^{\circ} \mathrm{C}$ on a magnetic stirrer. The colloidal solution was centrifuged at $10,000 \mathrm{rpm}$ for 10 minutes, and the obtained orange-yellow solid was washed with water, methanol, and acetone to remove biomolecules. The solid was then dried at $85^{\circ} \mathrm{C}$ and used for further characterization. The synthesized CdS NPs were characterized using UV-visible spectroscopy, X-ray diffraction (XRD), Fourier transform infrared spectroscopy (FTIR), dynamic light scattering (DLS), atomic force microscopy (AFM), and energy-dispersive X-ray spectroscopy (EDX) analyses.

\section{Analytical techniques}

The sample aliquots from different concentrations of extracts were monitored using a Hitachi double-beam UV-visible spectrometer (model: U-2800) in the range of $200-800 \mathrm{~nm}$ at a scan speed of $400 \mathrm{~nm} / \mathrm{min}$ with a resolution of $1 \mathrm{~nm}$. FTIR analysis was done using a Thermo Nicolet Avatar 330 FTIR for watermelon rind powder (WRP) and dried WRAE in the range of 4,000-400 $\mathrm{cm}^{-1}$ to determine the functional groups bound onto the CdS NPs. The powder XRD analysis of ovendried CdS NPs was carried out with a Bruker D8 Advance model equipped with a Lynx eye detector and beta Ni filter. The scanning was done in the range of $2 \theta$ from $10^{\circ}$ to $80^{\circ}$ at $0.02^{\circ} / \mathrm{min}$. The size and morphology of CdS NPs synthesized by WR extract were examined using a transmission electron microscope (Philips CM200 model). The samples were prepared on carbon-coated copper grids prior to the transmission electron microscopy (TEM) analysis. The particle size analysis was carried out by DLS (Delsa ${ }^{\mathrm{TM}}$ Nano).

\section{Results}

The WRAE was initially evaluated for identification of a capping agent responsible for synthesis of CdS NPs. The preliminary phytochemical analysis of the extract confirmed the presence of carbohydrates through Molisch's test by the formation of purple-colored ring with addition of concentrated $\mathrm{H}_{2} \mathrm{SO}_{4}$. Previous researchers have reported starch to be an effective capping agent for green synthesis of $\mathrm{CdS}$ and CdSe NPs..${ }^{90}$ But in the present case, water-soluble fractions of WR such as carbohydrates might act as a capping agent for synthesis of CdS NPs. The hydroxyl group of carbohydrates act as passivation contacts for the stabilization of the $\mathrm{CdS}$ NPs in the aqueous solution. ${ }^{11}$ A schematic representation of passivation of carbohydrates for stabilization of CdS NPs in aqueous solution is shown in Figure 1.

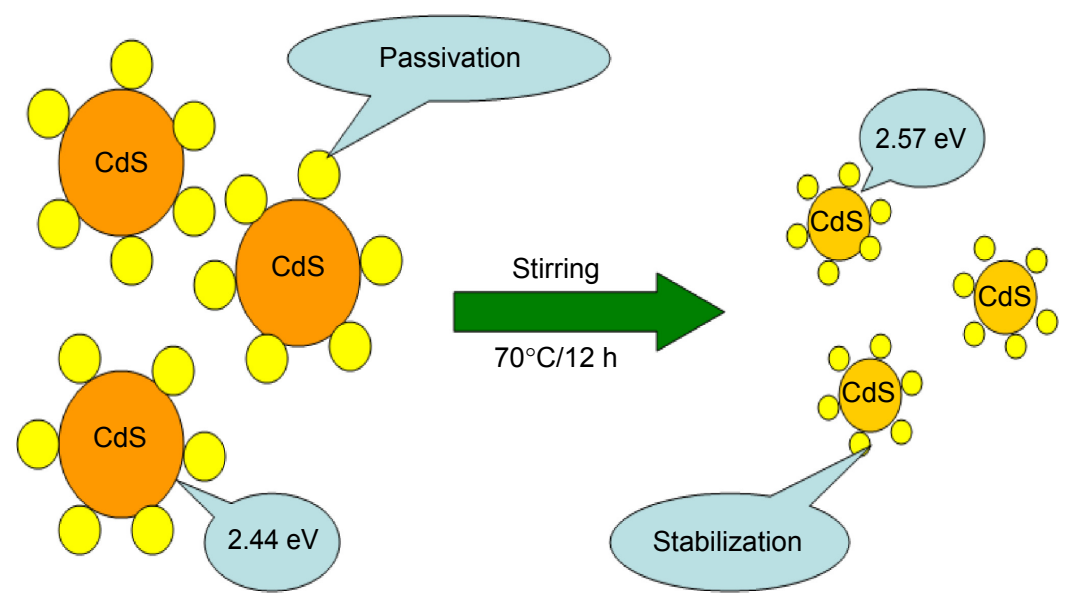

Figure I Plausible mechanism of CdS nanoparticles stabilized by watermelon rind aqueous extract. 
FTIR spectroscopy was used to analyze the type of organic capping agent adsorbed onto the surface of synthesized CdS NPs. The FTIR spectrum of synthesized CdS NPs shows strong bands at 3,416, 3,139, 2,924, 1,619, 1,400, 1,122 and $1,067 \mathrm{~cm}^{-1}$ (Figure 2A). The bands at 3,416 and $1,619 \mathrm{~cm}^{-1}$ correspond to symmetric and asymmetric stretching vibrations of -OH groups. Bands at 3,139 and 2,924 $\mathrm{cm}^{-1}$ correspond to aromatic and aliphatic $-\mathrm{CH}$ stretching vibrations. A peak at $1,400 \mathrm{~cm}^{-1}$ corresponds to $-\mathrm{CH}$ bending vibrations and peaks at 1,122 and $1,067 \mathrm{~cm}^{-1}$ are due to symmetrical and asymmetrical bending vibrations of aromatic - $\mathrm{CH}$ groups. It has been reported that $\mathrm{CdS}$ can give a very weak absorption band at $405 \mathrm{~cm}^{-1} \cdot{ }^{12}$ A very weak band was observed at $405 \mathrm{~cm}^{-1}$, which corresponds to CdS NPs (Figure 2B). The bands from the FTIR spectra confirmed that carbohydrates were present on the surface of the CdS NPs as capping and stabilizing agents.

The formation of CdS NPs was monitored by UV-visible spectroscopy. An absorption maximum at $484 \mathrm{~nm}$ with a band gap of $2.57 \mathrm{eV}$ was observed, which was due to the quantum size effect of formed CdS NPs. ${ }^{13}$ The band gap of bulk CdS before addition of WRAE was found to be $2.44 \mathrm{eV}$; this could be due to the consequence of a size quantization effect in the sample. ${ }^{14}$ The extract concentration was varied in order to study the effect on size confinement. It was observed that the highest extract concentration resulted in size-controlled CdS NPs. The results were confirmed by DLS analysis. In order to determine the elemental composition of synthesized NPs, the EDX pattern was recorded. The EDX pattern of synthesized
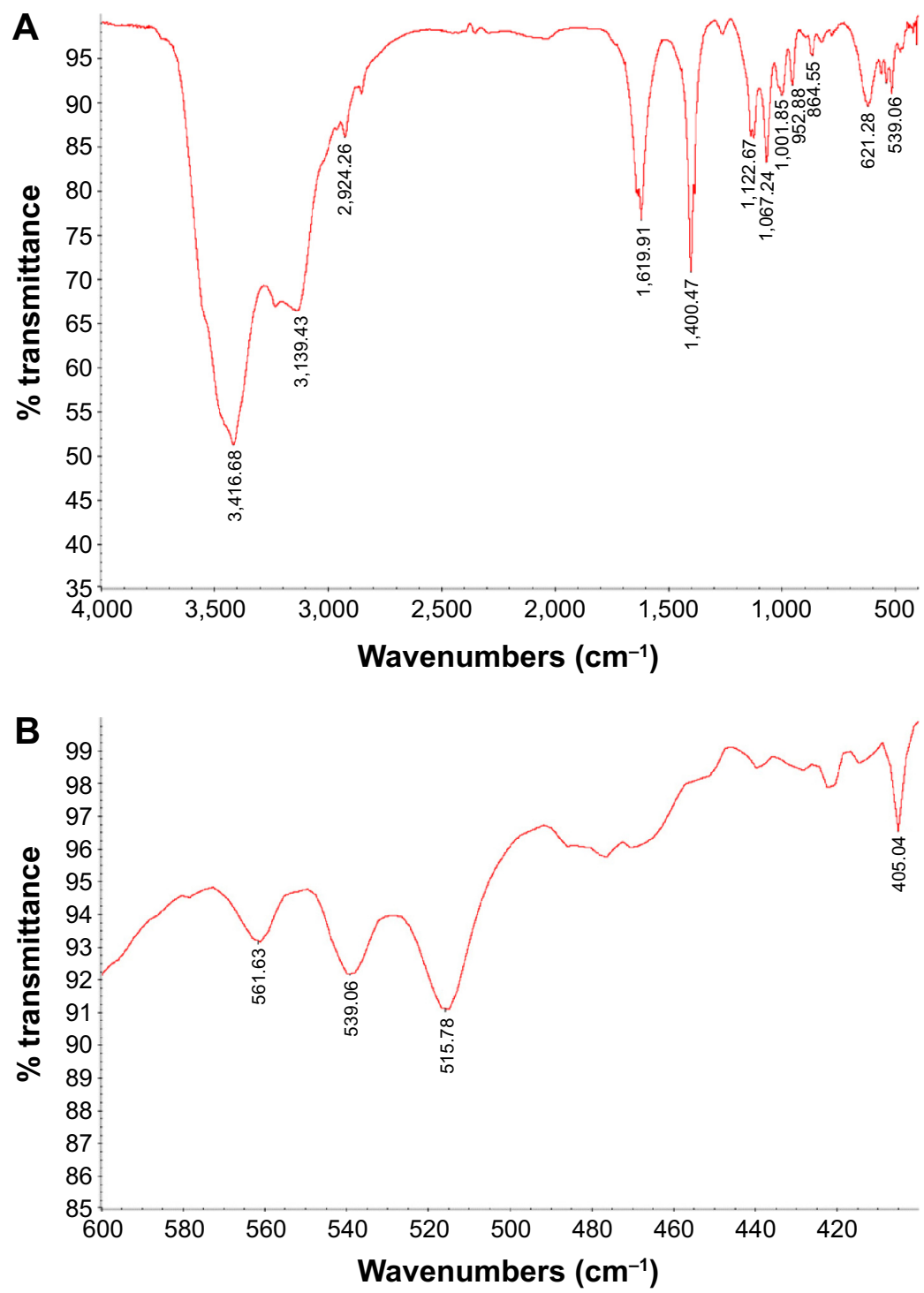

Figure 2 Fourier transform infrared spectroscopy spectra of CdS nanoparticles stabilized by watermelon rind aqueous extract. Notes: (A) Full range. (B) Depiction of CdS peak. 


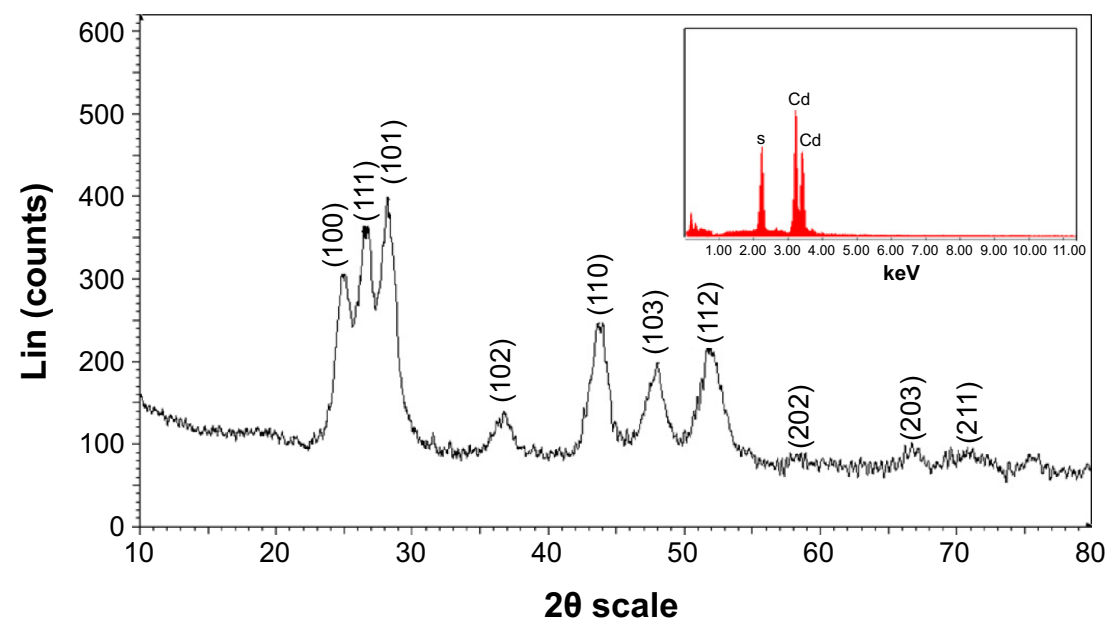

Figure 3 X-ray diffraction and energy-dispersive X-ray spectroscopy (inset) patterns of CdS nanoparticles fabricated using watermelon rind aqueous extract.

NPs showed strong signals of Cd and S alone (Figure 3 [inset]), without contamination by other atoms.

XRD analysis was done for the WRAE-synthesized CdS NPs to confirm the crystalline nature (Figure 3). The XRD patterns showed the presence of broad peaks at $2 \theta$ values of $24.90,26.53,28.14,43.63,47.99$, and 51.75, respectively, which is attributed to the (100), (111), (101), (110), (103), and (112) diffraction planes of hexagonal-structure CdS NPs, corresponding to the JCPDS number 80-0006. The broad peaks indicate the particles were of very small crystallite size. The mean crystallite size was calculated to be $28 \mathrm{~nm}$ using the Scherrer formula. ${ }^{15}$ The results indicated that WRE acted as a stabilizing and capping agent in the preparation of the hexagonal CdS NPs.

DLS analysis (Figure 4) was performed in order to determine the particle size distribution of the synthesized CdS NPs mediated by WRAE. It can be seen from Figure 4 that around $94 \%$ of CdS NPs were $90 \mathrm{~nm}$ in size. The particle sizes of CdS NPs determined using DLS were corroborated

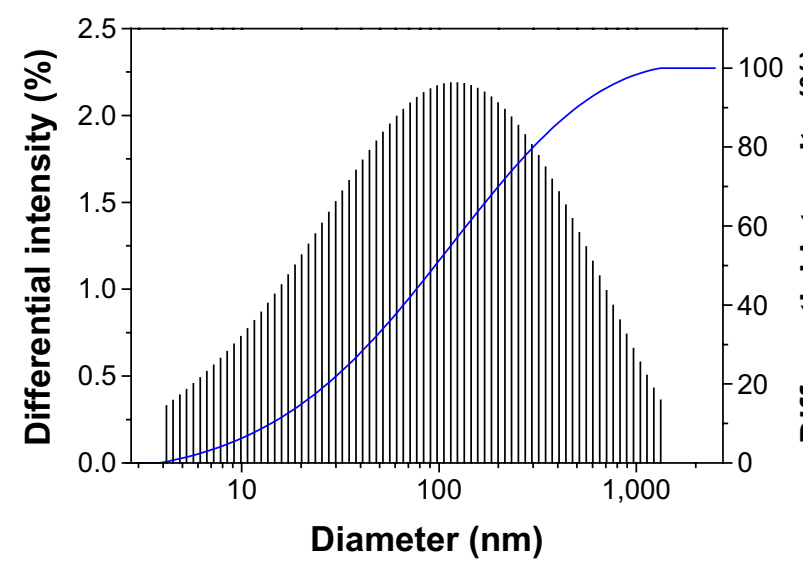

Figure 4 Particle size plot of synthesized CdS nanoparticles stabilized by watermelon rind aqueous extract. with AFM analysis. The size and shape of CdS NPs were found to be stable even after 3 months of synthesis. TEM analysis was carried out in order to determine the shape of the as-synthesized CdS NPs.

A TEM image of CdS NPs is shown in Figure 5. The image indicates CdS NPs were shape controlled with a diameter range of $90 \mathrm{~nm}$. This was confirmed by the XRD and AFM analyses.

Figure 6 shows a typical AFM image (Easyscan 2; Nanosurf, Liestal, Switzerland) of CdS NPs stabilized by WR. Most of the NPs were found to range in size between 80 and $90 \mathrm{~nm}$, which is larger than the values calculated from the XRD pattern.

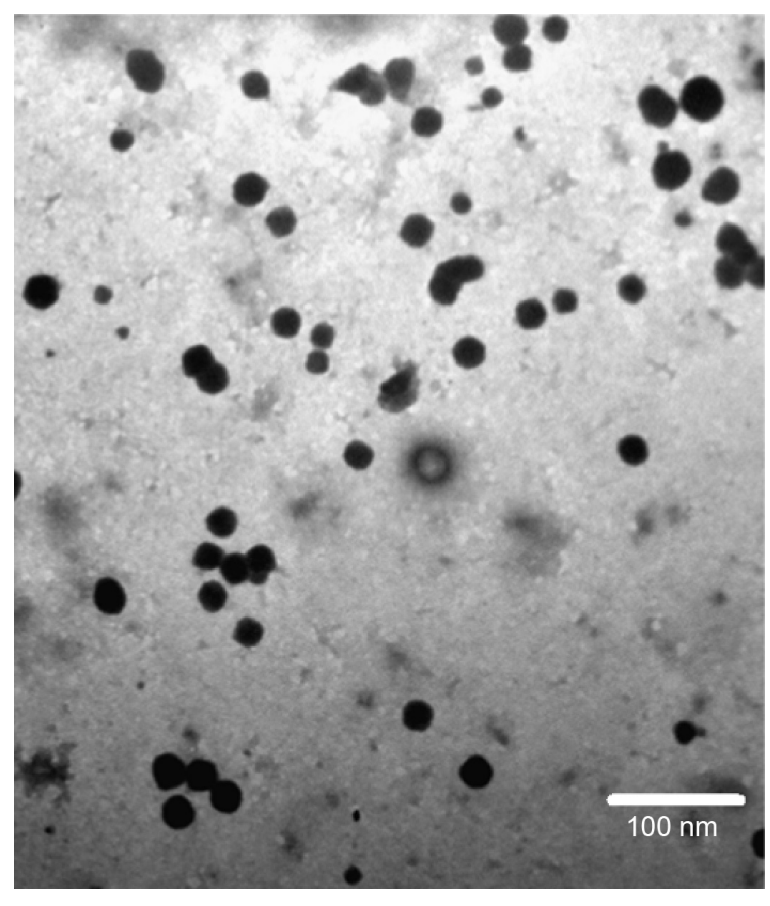

Figure 5 Transmission electron microscopy image of watermelon rind aqueous extract-stabilized CdS nanoparticles. 
A

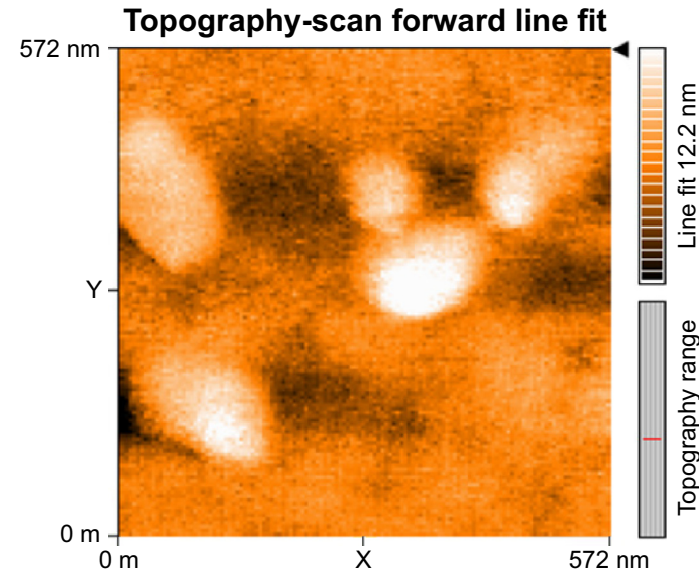

\section{B Deflection-scan forward line fit}

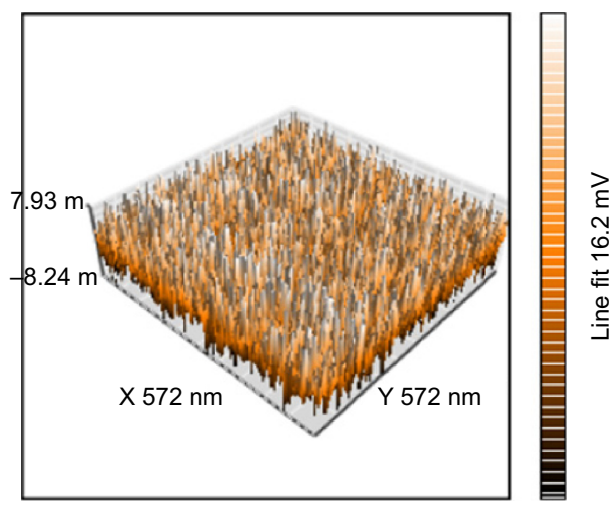

Figure 6 Atomic force microscopy image of synthesized CdS nanoparticles.

Notes: (A) Topography-scan forward line fit and (B) deflection-scan forward line fit.

The larger particles from the AFM image can be ascribed to the aggregation of the smaller particles. ${ }^{16}$ The mean surface roughness was measured and calculated to be $16 \mathrm{~nm}$ by AFM, which indicates that relatively uniform CdS NPs were synthesized by the one-step green process.

\section{Conclusion}

One-pot green synthesis of CdS NPs was successfully performed using the aqueous extract of WR, an agro-waste. Water-soluble carbohydrates present in WRAE were believed to be the capping and stabilizing agent for the CdS NP formation. The capping of biomolecules onto CdS NPs from WRAE was confirmed by FTIR analysis. The average particle size of CdS NPs was found to be around $90 \mathrm{~nm}$. The shapes of the particles were spherical, confirmed by TEM analysis. The surface roughness was measured and calculated to be 16 $\mathrm{nm}$ by AFM. Thus, it is proved that WR, an agro-waste, has been effectively used as a capping and stabilizing agent for synthesis of CdS NPs using a green chemistry approach.

\section{Acknowledgments}

The authors gratefully acknowledge the management of VIT University, Vellore, India for encouragment, and providing the necessary facilities for carrying out this work, and we thank Johnson \& Johnson for the publication sponsorship.

\section{Disclosure}

The authors report no conflicts of interest in this work.

\section{References}

1. Wada Y, Kuramoto H, Anand J, et al. Microwave-assisted size control of CdS nanocrystallites. J Mater Chem. 2001;11:1936-1940.

2. Talapin DV, Poznyak SK, Gaponik NP, Rogach AL, Eychmüller A. Synthesis of surface-modified colloidal semiconductor nanocrystals and study of photoinduced charge separation and transport in nanocrystal-polymer composites. Physica E Low Dimens Syst Nanostruct. 2002;14:237-241.
3. Mane RS, Lokhande CD. Chemical deposition method for metal chalcogenide thin films. Mater Chem Phys. 2000;65:1-31.

4. Wang GZ, Chen W, Liang CH, Wang YW, Meng GW, Zhang LD Preparation and characterization of CdS nanoparticles by ultrasonic irradiation. Inorg Chem Commun. 2001;4:208-210.

5. Prasad K, Jha AK. Biosynthesis of CdS nanoparticles: an improved green and rapid procedure. J Colloid Interface Sci. 2010;342:68-72.

6. Lakshmipathy R, Vinod AV, Sarada NC. Watermelon rind as biosorbent for removal of $\mathrm{Cd}^{2+}$ from aqueous solution: FTIR, EDX and Kinetic studies. Journal of the Indian Chemical Society. 2013;90:1147-1154.

7. Jayaprakasha GK, Chidambara Murthy KN, Bhimanagouda S Patil. Rapid HPLC-UV method for quantification of L-citrulline in watermelon and its potential role on smooth muscle relaxation markers. Food Chem. 2011;127:240-248.

8. Lakshmipathy R, Sarada NC. Application of watermelon rind as sorbent for removal of nickel and cobalt from aqueous solution. International Journal of Mineral Processing. 2013;122:63-65.

9. Wei Q, Kang SZ, Mu J. "Green" synthesis of starch capped CdS nanoparticles. Colloids Surf A Physicochem Eng Asp. 2004;247: $125-127$.

10. Li JH, Ren CL, Liu XY, Hua ZD, Xue DS. "Green" synthesis of starch capped CdSe nanoparticles at room temperature. Material Science Engineering A. Structural Materials. 2007;458:319-322.

11. Rodriguez P, Muñoz-Aguirre N, San-Martín Martinez E, González de la Cruz G, Tomas SA, Zelaya Angel O. Synthesis and spectral properties of starch capped CdS nanoparticles in aqueous solution. J Cryst Growth. 2008;310:160-164.

12. Wu D, Ge X, Zhang Z, Wang M, Zhang S. Novel one-step route for synthesizing $\mathrm{CdS} /$ polystyrene nanocomposite hollow spheres. Langmuir. 2004;20:5192-5195.

13. Liu JK, Luo CX, Yang XH, Zhang XY. Ultrasonic-template method synthesis of CdS hollow nanoparticle chains. Mater Lett. 2009;63: 124-126.

14. MubarakAli D, Gopinath V, Rameshbabu N, Thajuddin N. Synthesis and characterization of $\mathrm{CdS}$ nanoparticles using C-phycoerythrin from the marine cyanobacteria. Mater Lett. 2012;74:8-11.

15. Cullity BD. Elements of X-ray diffraction. 2nd ed. Reading, MA: Addison-Wesley; 1978.

16. Taubert A, Wegner G. Formation of uniform and monodisperse zincite crystals in the presence of soluble starch. J Mater Chem. 2002; $12: 805-807$ 


\section{Publish your work in this journal}

The International Journal of Nanomedicine is an international, peerreviewed journal focusing on the application of nanotechnology in diagnostics, therapeutics, and drug delivery systems throughout the biomedical field. This journal is indexed on PubMed Central, MedLine, CAS, SciSearch $\AA$, Current Contents ${ }^{\circledR} /$ Clinical Medicine,
Journal Citation Reports/Science Edition, EMBase, Scopus and the Elsevier Bibliographic databases. The manuscript management system is completely online and includes a very quick and fair peer-review system, which is all easy to use. Visit http://www.dovepress.com/ testimonials.php to read real quotes from published authors.

Submit your manuscript here: http://www.dovepress.com/international-journal-of-nanomedicine-journal 